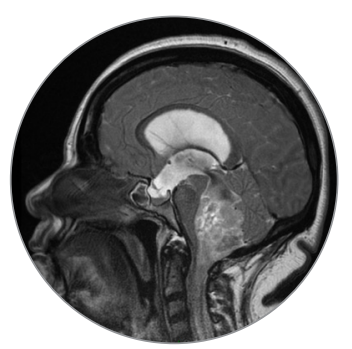

\title{
Diagnóstico diferencial de las lesiones del IV ventrículo
}

\author{
Differential Diagnosis of Fourth Ventricular Lesions
}

\author{
Katiuska Casares \\ Ana Teresa Araújo ${ }^{2}$ \\ Carlos Andrés Arias Durán²
}

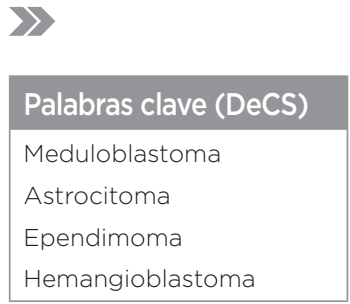

Key words (MeSH)

Medulloblastoma

Astrocytoma

Ependymoma

Hemangioblastoma
'Neurorradióloga, Instituto Neurología y Neurocirugía Manuel Velasco Suárez. Bucaramanga, Colombia.

${ }^{2}$ Radióloga(o), Universidad Autónoma de Bucaramanga. Bucaramanga, Colombia.

\section{Resumen}

La población pediátrica es, de lejos, la más afectada por las lesiones del cuarto (IV) ventrículo. La gran mayoría presentan un patrón radiológico similar; actualmente, con las secuencias de difusión, espectroscopia y mapas de ADC, se puede inferir la compatibilidad de los hallazgos visualizados con alguna de las patologías que se revisarán en el presente trabajo.

\section{Summary}

The pediatric population is by far the most affected by lesions of the fourth (IV) ventricle. The vast majority present a similar radiological pattern, for which today, with the diffusion sequences, spectroscopy and ADC maps, it can be inferred that the visualized findings are more likely compatible with some of the pathologies that we will review later.

\section{Introducción}

Las lesiones que comprometen el cuarto ventrículo son más frecuentes en la población pediátrica y las más comunes son meduloblastoma, astrocitoma pilocítico y ependimoma; en adultos las más frecuentes son el hemangioblastoma, subependimoma y las metástasis. Muchas de estas lesiones tienen un patrón similar en cuanto a densidad o intensidad y realce, por lo tanto, se debe intentar obtener un diagnóstico diferencial lo más preciso posible, utilizando los datos clínicos y demográficos y los hallazgos imagenológicos.

El IV ventrículo es una cavidad de líquido cefalorraquídeo (LCR) que se continúa hacia arriba con el acueducto de Silvio y se abre hacia abajo y lateralmente al espacio subaracnoideo por los agujeros de Luschka y Magendie. Tiene una pared anteroinferior o piso, constituida por protuberancia y bulbo, y una posterosuperior o techo, que termina en punta a la altura del fastigio o receso posterior, constituida por el cerebelo y la tela coroidea posterior (1).

El cuarto ventrículo, como el resto del sistema ventricular, está revestido por epitelio de células ependimarias y células gliales subependimarias, contiene plexos coroideos que son las estructuras vascularizadas encargadas de la producción de LCR (1).

Las lesiones que pueden ocupar el IV ventrículo se clasifican en dos tipos principales en función de su origen. Las primarias derivadas del epitelio ependimario, subependimario, plexos coroideos y tejido aracnoideo. Las secundarias son lesiones paraventriculares con un crecimiento exofítico que provoca invasión del ventrículo (2).
Dentro de las lesiones primarias están las que se originan de los plexos coroideos, como el papiloma y el carcinoma de plexos coroideos, meningiomas y metástasis. Las lesiones que se originan de la pared del ventrículo incluyen el ependimoma y subependimoma (3). Los procesos no neoplásicos que se ubican dentro del cuarto ventrículo incluyen neurocisticercosis y tuberculomas.

Las lesiones secundarias o extraventriculares con crecimiento exofítico y componente intraventricular incluyen dos tercios de las lesiones intraaxiales, como meduloblastoma, hemangioblastoma y astrocitoma pilocítico $(4,5)$.

\section{Clasificación de las lesiones}

\subsection{Lesiones primarias}

\subsubsection{Papiloma y carcinoma de plexos coroideos}

Los tumores de plexos coroideos son tumores primarios del sistema nervioso central, de origen neuroepitelial. Su incidencia anual aproximada se estima en $0,3 \times 1.000 .000$ de habitantes. Representan entre $2-4 \%$ de los tumores cerebrales pediátricos $(20 \%$ en el primer año de vida) y el $0,5 \%$ de todos los tumores cerebrales del adulto (4). Cuanto más caudal es el tumor, mayor es la edad de aparición, con una media de edad de inicio de 1,5 años en los ventrículos laterales y III ventrículo, y de 22,5 años en el IV ventrículo $(6,7)$.

La Organización Mundial de la Salud (OMS) divide los tumores de plexos coroideos en 3 tipos, con sus correspondientes grados: papiloma de plexos coroideos 
(PPC) Grado I OMS; papiloma atípico o anaplásico de plexos coroideos, Grado II OMS, y carcinoma de plexos coroideos (CPC) Grado III OMS. Los papilomas atípicos se caracterizan por tener una histología similar a los papilomas de plexos coroideos, pero con aumento de la actividad mitótica, con al menos 2 o más mitosis en 10 campos de gran aumento. Los carcinomas de plexos coroideos tienen 5 o más mitosis en 10 campos. El pronóstico para los pacientes con PPC es bueno, con una tasa de supervivencia a 5 años del $97 \%$, pero en el CPC esta tasa se reduce al $26-43 \%(3,4,8)$.

Estos pacientes se presentan con hidrocefalia como resultado del aumento en la producción de LCR por la neoplasia, por obstrucción directa al flujo de líquido cefalorraquídeo y disminución de la reabsorción por exudado proteínico y hemorragia que afecta las vellosidades aracnoideas (4).

\section{Hallazgos en imágenes}

Estas lesiones intraventriculares muestran contornos bien definidos, forma de coliflor, son muy vascularizados, por lo que son comunes las hemorragias y quistes. Aunque imagenológicamente no se pueden diferenciar los grados histológicos, los papilomas y papilomas atípicos tienen aspecto lobulado; los carcinomas de plexos coroideos tienden a tener un contorno más irregular, son heterogéneos por necrosis e invaden más el parénquima cerebral (9-11)

En tomografia computarizada (TC) se observan como lesiones intraventriculares de media o alta densidad, que pueden tener calcificaciones y zonas de hemorragia, realzan ávidamente con el medio de contraste (figura 2).

En resonancia magnética (RM) se observa en el PPC un tejido de media o baja señal en secuencias con información T1, de media o alta señal en secuencias con información en T2 y con vacíos de señal comunes por flujo (9). Puede observarse edema vasogénico periventricular y realce intenso homogéneo debido a la alta vascularización. No muestran signos de restricción a la difusión del agua. En las secuencias de perfusión reflejan flujo arterial alto, el cual no regresa a la línea de base por pérdida de la barrera hematoencefálica, con una persistencia del medio de contraste en el intersticio $(4,9,12)$.

En la secuencia de espectroscopia se observa pico de colina (Cho) elevado y ausencia del pico de $\mathrm{N}$-acetil-aspartato (NAA). Los CPC muestran pico elevado del lactato debido al aumento de la proliferación celulary la glucólisis anaeróbica. Algunos autores refieren aumento del pico de mioinositol en los papilomas a diferencia de los carcinomas $(2,9,11,13-15)$ (figuras 1 y 2).

\subsubsection{Ependimoma}

Representa el 2-5\% de las neoplasias intracraneales en adultos (16), pero es el tercer tumor de fosa posterior más frecuente en niños después del astrocitoma pilocítico y el meduloblastoma, con una edad media de presentación de 6 años. Es un tumor glial que surge de las células ependimarias de la pared ventricular y del epéndimo medular $(4,16,17)$.

Según la clasificación de la OMS se dividen en ependimoma mixopapilar grado I, ependimoma grado II, ependimoma fusión RELA positivo grado II-III y ependimoma anaplásico grado III. Los ependimomas de localización supratentorial tienen peor pronóstico y mayores tasas de recaída que los ubicados en fosa posterior $(8,18-20)$.

\section{Hallazgos en imágenes}

Los ependimomas que se originan en el IV ventrículo tienden a llenar el ventrículo y a adoptar su forma, por lo que pueden extenderse a través del foramen de Luschka o de Magendie o el foramen magnum. Es frecuente observar un componente quístico y áreas de calcificación irregulares, y eventualmente zonas de hemorragia intratumoral $(12,17)$.

En TC los ependimomas muestran media o baja densidad y en RM tienen señal media a baja, en secuencias con información T1 y de media a alta señal en secuencias con información T2. Puede haber edema vasogénico en la sustancia blanca periventricular. Tienen realce heterogéneo con el medio de contraste, así como focos de ausencia de señal por calcificación o hemorragia en secuencias de susceptibilidad magnética $(3,4)$ (figura3). En la difusión su señal es variable, dependiendo de la celularidad del tumor, con valores generalmente intermedios del coeficiente de difusión aparente (ADC) $(11,21)$.

En espectroscopia los ependimomas tienen un patrón neoplásico con reducción del pico de NAA y moderada elevación del lactato y de la colina. En algunos casos presentan alto el pico de mioinositol (mI) y el de glicina (Gly) con relativa preservación del pico de NAA. Sin embargo, la espectroscopia por si sola no los diferencia de otros tumores $(9,11,21-23)$.

En la secuencia de perfusión, los ependimomas demuestran el volumen sanguíneo cerebral marcadamente elevado y, a diferencia de otros tumores gliales, tienen pobre retorno a la línea de base por la alteración de la barrera hematoencefálica $(11,22)$ (figura 3 ).

\subsubsection{Subependimoma}

Representan el 0,7 \% de las neoplasias intracraneales. La mayoría de estas lesiones aparecen en el IV ventrículo (50-60\%). Surgen de la capa glial subependimaria que rodea los ventrículos. Predominan en el sexo masculino 2:1, y el $82 \%$ se presenta en pacientes mayores de 15 años. Su pronóstico es bueno y la recurrencia después de la resección quirúrgica es poco frecuente $(2,3,12,24)$.

Solo un tercio de los pacientes tienen manifestaciones clínicas, especialmente los que se originan del piso del cuarto ventrículo, secundarias a obstrucción al flujo de LCR. La clínica más frecuente es cefalea, vómito, mareo y vértigo (25), y menos frecuentemente con déficit neurológico focal y convulsiones (26). Los subependimomas son neoplasias grado I de la OMS (8).

\section{Hallazgos en imágenes}

Los subependimomas son lesiones bien circunscritas, pequeñas, con diámetro menor de $2 \mathrm{~cm}$. Pueden mostrar degeneración quística, calcificación o hemorragia intratumoral. A diferencia de los ependimomas no suele existir invasión extraventricular $(4,11,25)$.

En TC se observan como masas de baja a media densidad, intraventriculares, de contornos bien definidos. En RM son lesiones de baja a media señal en secuencias con información T1, de alta señal con información T2 y FLAIR, sin edema del parénquima adyacente, y pueden expresar focos de ausencia de señal por calcificación o hemorragia en secuencias de susceptibilidad magnética. La mayoría de las lesiones tienen escaso o nulo realce ya que son tumores avasculares $(3,11,24)$ (figura 4).

Los subependimomas muestran mayor difusión libre que el parénquima adyacente, tienen alta señal en los mapas de ADC. En los estudios de perfusión presentan muy bajo volumen sanguíneo cerebral, en las secuencias de espectroscopia demuestran un pico de colina normal y disminución de NAA. En raras ocasiones demuestran aumento de la relación colina/creatina (27). 

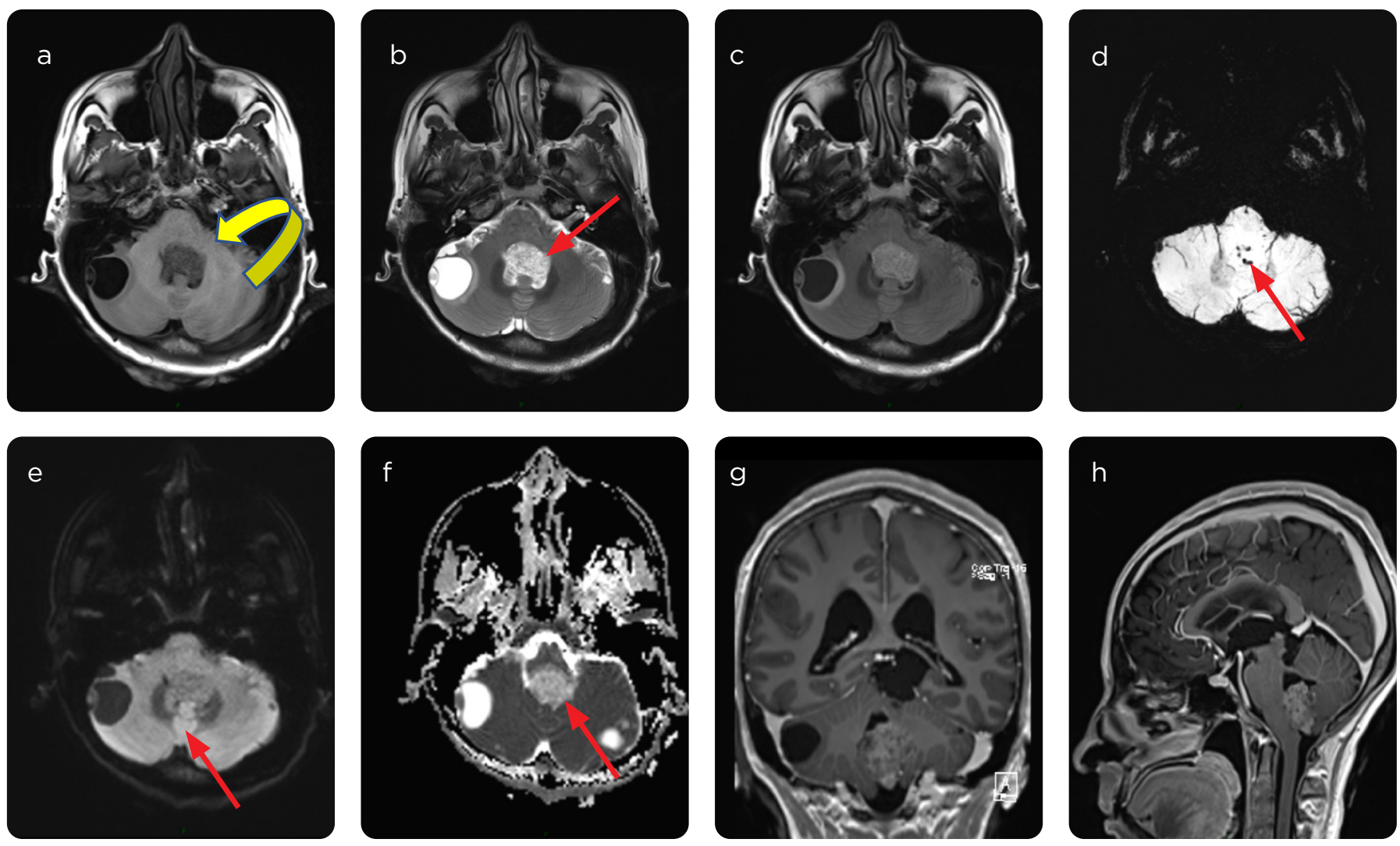

Figura 1. Papiloma del IV ventrículo RM. a) Secuencia con información T1: baja señal. b) Secuencia eco de espín; y c) secuencia FLAIR con información T2: alta señal. d) Secuencia de susceptibilidad magnética; baja señal atribuida a calcio. e) Secuencia de difusión y f) mapa ADC: no tiene restricción a la difusión de agua. $g$ y h) Con medio de contraste: realce heterogéneo atribuido a calcio.
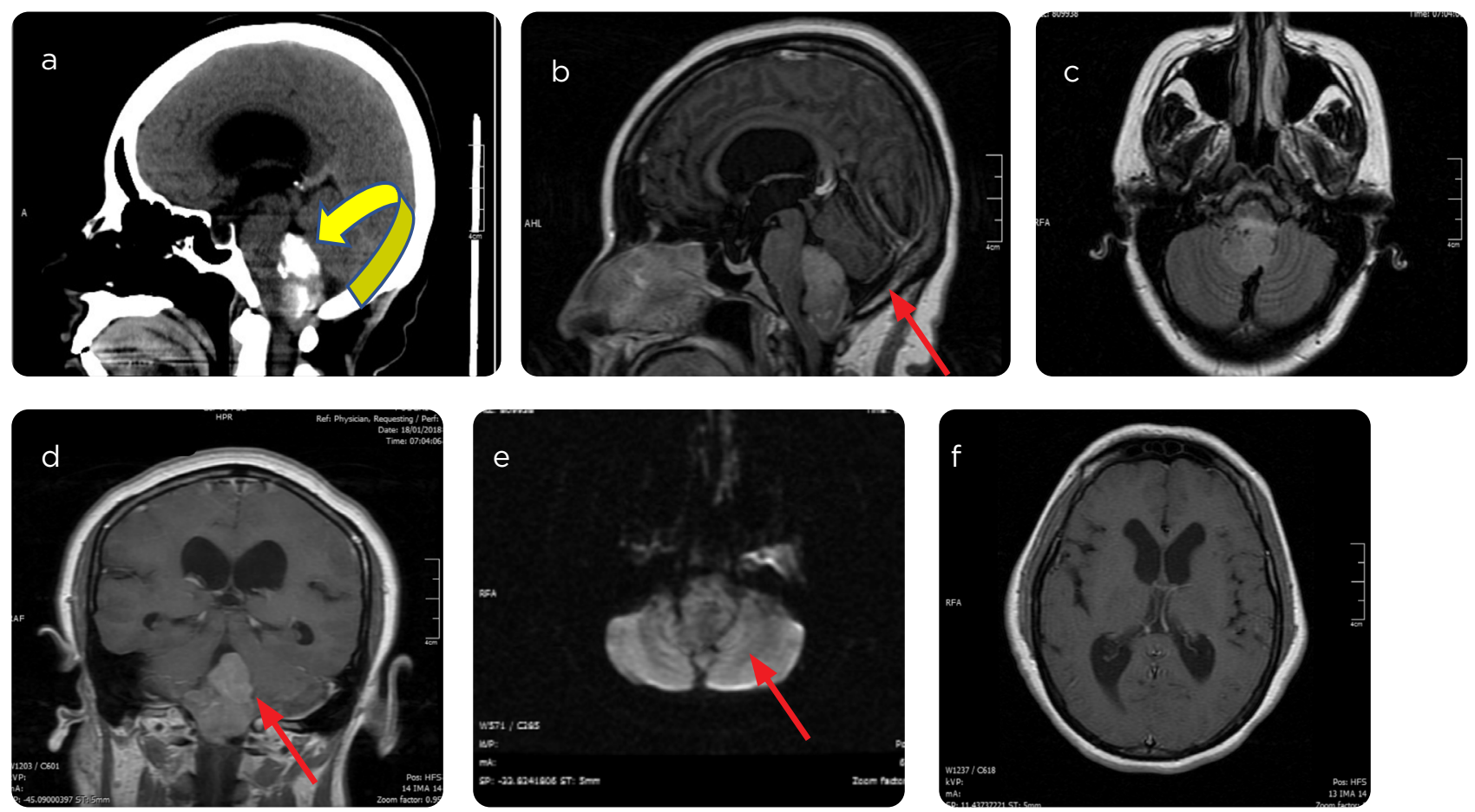

Figura 2. Carcinoma de plexo coroideo del IV ventrículo. a) TC densidad heterogénea con áreas isodensas al parénquima y calcificaciones. b) RM con información en T1: isointensa al parénquima cerebral. c) Secuencias con información T2 de señal intermedia a alta. d) Con medio de contraste: presenta realce. e) Secuencia de difusión: no presenta restricción a la difusión del agua. f) Imagen axial supratentorial: dilatación del sistema ventricular. 

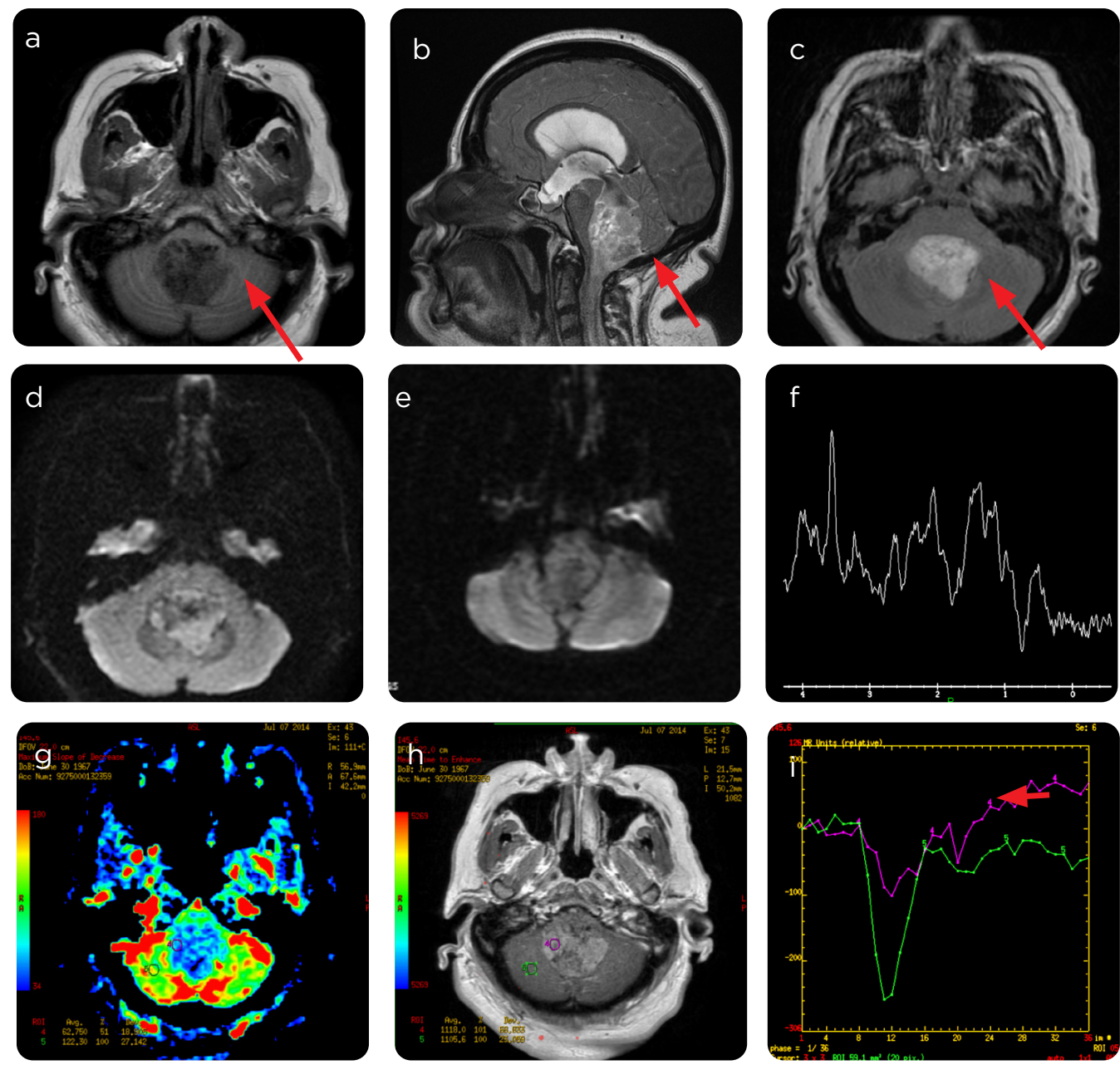

Figura 3. Ependimoma en el IV ventrículo. a) RM secuencia axial con información T1, de señal baja a intermedia. b) Con medio de contraste: realce intenso y discretamente heterogéneo. c) Secuencia con información T2: señal predominantemente alta. d) Secuencia de difusión: señal intermedia. e y f) Perfusión: alto volumen sanguíneo cerebral sin retorno a la línea de base.
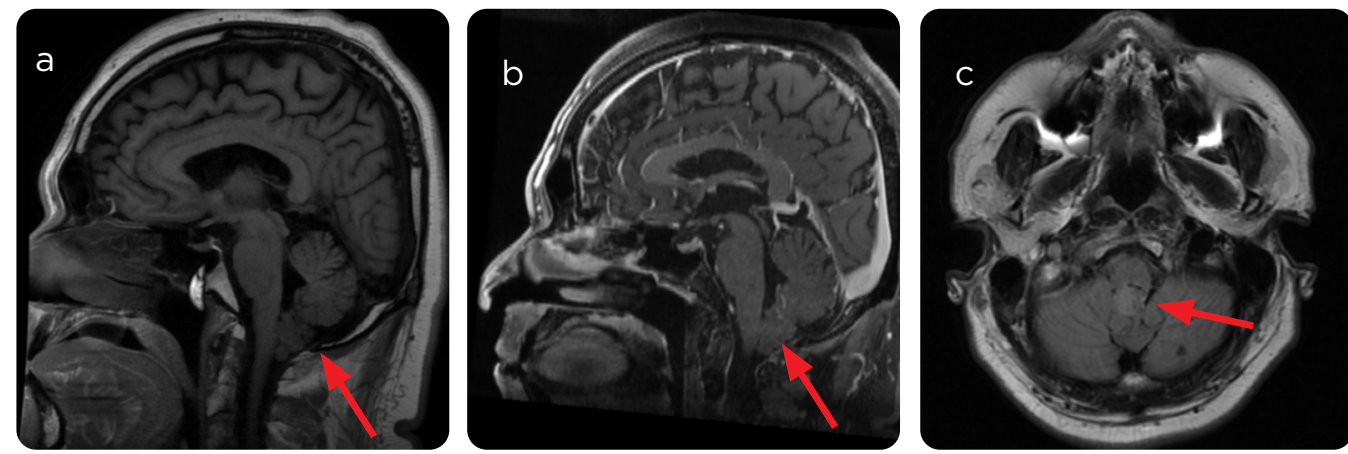

Figura 4. Subependimoma de velo medular inferior del cuarto ventrículo. a) RM con información T1: lesión de señal intermedia. b) Con medio de contraste: escaso realce. c y d) Secuencia FLAIR; y e) Eco de espín con información T2: señal discretamente alta. e) Secuencia de difusión: sin restricción a la difusión de agua.
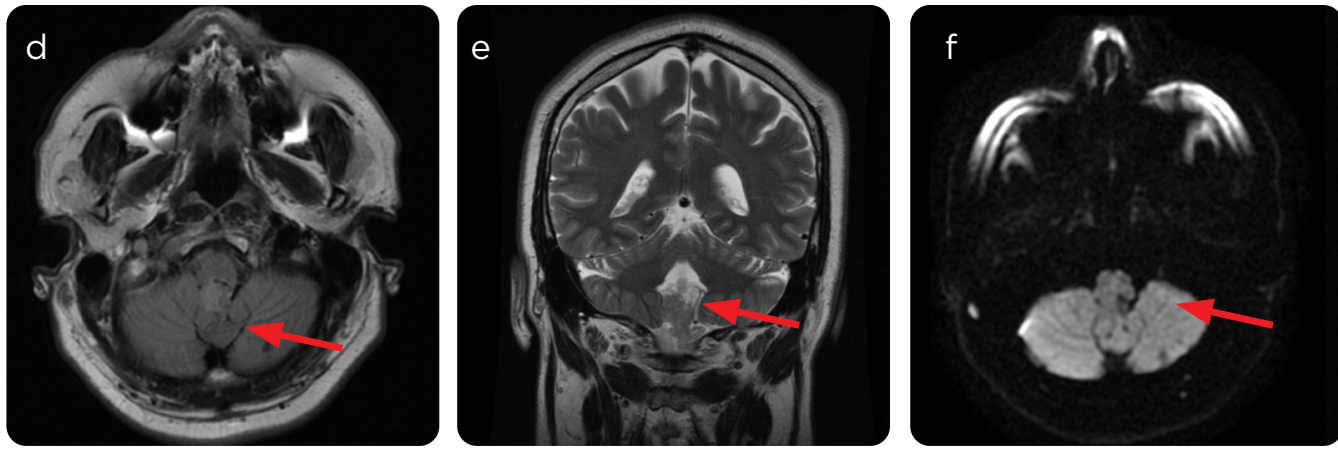


\subsubsection{Meningiomas}

Los meningiomas intraventriculares representan el 0,5-3,7 \% de los meningiomas intracraneales. Surgen de las células aracnoideas atrapadas en el plexo coroideo o de la tela coroidea durante la formación embriológica de la fisura coroidea y el plexo. De los meningiomas intraventriculares 77,8 \% ocurren en los ventrículos laterales, $15,6 \%$ en el tercer ventrículo y $6,6 \%$ en el cuarto ventrículo $(2,11,28,29)$. Estas neoplasias de lento crecimiento usualmente alcanzan grandes tamaños antes de mostrar síntomas, los cuales son hipertensión intracraneana, déficit sensorial o motor contralateral y también pueden presentar hemorragia intraventricular $(3,29)$.

\section{Hallazgos en imágenes}

Los meningiomas son lesiones bien circunscritas de contornos regulares, pueden calcificarse (50\%) y tener áreas quísticas. En TC se observan con media o alta densidad en referencia al tejido cerebral; en RM son de baja a media señal en las imágenes potenciadas T1, de media a alta señal en T2, pueden mostrar edema periventricular secundario a reabsorción del LCR subependimario o a la secreción del factor de crecimiento endotelial vascular por el meningioma $(3,4,29)$.

Son altamente vascularizados y realzan con intensidad con el medio de contraste. En las secuencias de difusión pueden mostrar una reducción de la velocidad de difusión por la alta densidad celular (9,30-32).

En las secuencias de perfusión, los meningiomas muestran elevación del volumen sanguíneo cerebral, con persistencia del material de contraste en el intersticio del tumor debido a la falta de una barrera hematoencefálica $(2,11,27,33)$.

En las secuencias de espectroscopia el nivel de colina es elevado, con cantidades variables de lactato y lípidos. Un pico de alanina, cuando se presente, puede ser útil en su diagnóstico (doblete centrado a 1,47 ppm). Por ser una lesión mesenquimal sin tejido neuronal, no muestra pico de NAA $(4,9,11,22)$.

\subsection{Lesiones secundarias}

\subsubsection{Meduloblastoma}

Es el tumor cerebral maligno de fosa posterior más frecuente en niños, representa el 20-25\% de los tumores cerebrales en pediatría y el $40 \%$ de los tumores de fosa posterior. Es un tumor embrionario invasivo OMS grado IV, con tendencia inherente a hacer metástasis en el eje craneoespinal, a través del espacio subaracnoideo (11-43\%), de lo que depende su pronóstico. La edad media de debut es de 5-7 años $(12,34,35)$.

Histológicamente, según la revisión de la OMS 2016, se clasifican en: clásico (65-85\%), desmoplásico-nodular (15-25\%) y con nodularidad extensa (5\%), y anaplásico/células grandes (4-5\%). Con el advenimiento de la medicina molecular se ha clasificado en 4 grupos genéticos. El grupo Wnt/B-catenina (WNT) es el menos común (10\%) y el de mejor pronóstico, con una sobrevida a 5 años del $94 \%$, el cual generalmente compromete el aspecto dorsal del tallo cerebral. El tipo Sonic-Hedgehog (SHH) (30\%) con sobrevida a 5 años hasta $87 \%$ depende de la mutación TP53. El grupo 3 (25\%) con sobrevida a 5 años de $32 \%$ es el de peor pronóstico. El grupo 4 es el más común (35-40\%), con sobrevida a 5 años de $76 \%(8,12,36-39)$.

\section{Hallazgos en imágenes}

En TC el meduloblastoma aparece típicamente como una masa homogénea localizada cerca o en la línea media, de contornos bien definidos, con media a alta densidad comparada con el parénquima cerebeloso adyacente, con edema vasogénico peritumoral que, después de la administración de medio de contraste, realza de manera difusa homogénea o heterogénea. Se pueden encontrar calcificaciones hasta en un $20 \%$ de los casos y áreas de necrosis quística que no realzan hasta en el $50 \%$ de los casos, la hemorragia intratumoral es rara $(17,34,36)$.

En RM es variable la apariencia del meduloblastoma, pueden observarse como masas redondeadas ligeramente lobuladas, con media o baja señal con información T1, de señal heterogénea en T2, la porción sólida frecuentemente tiene baja a media señal comparada con el parénquima cerebeloso. Usualmente realzan con la administración de medio de contraste, aunque de manera variable $(34,36,37)$ (figura 5).

En las secuencias de espectroscopia muestran aumento del pico de colina con disminución del pico de NAA y de mioinositol. Las secuencias de TE corto muestran aumento de la taurina en 3,36 ppm por incremento de la proliferación celular $(12,22,36)$.

En la secuencia de difusión, los meduloblastomas muestran alta señal en imagen de difusión y baja señal en ADC, con valores bajos de velocidad de difusión, secundario a la alta celularidad del tumor que disminuye el espacio intersticial y reduce la difusión de agua (40-45) (figura 5).

En la secuencia de perfusión se observa aumento del volumen sanguíneo cerebral relativo (rCBV) con un valor promedio de 2 , en el rango de los gliomas de alto grado (11-5.3) (46). La curva de circulación del medio de contraste demuestra ruptura de la barrera hematoencefálica con acumulación en la matriz extracelular, más que neoangiogénesis que sobrepasa la línea de base $(41,46)$.

\subsubsection{Astrocitoma pilocítico}

El astrocitoma cerebeloso es el tumor de fosa posterior más frecuente en niños y corresponde aproximadamente al 30-35 \% de los casos. Tiene un pico de incidencia entre los 5-13 años y afecta por igual a niños y niñas. El astrocitoma pilocítico es raro en adultos, con una incidencia menor a $0,1 \times 100.000$ habitantes, se manifiesta en mayores de 45 años, predominantemente en los hemisferios cerebelosos. Tiene un comportamiento muy poco agresivo con un crecimiento lento, y se clasifica como astrocitoma grado I por la OMS $(5,12,34,47,48)$.

La apariencia clásica en el cerebelo es de tumor quístico con nódulo mural hipercaptante, existe la forma sólido-quística — la más frecuente-, pero predomina en las otras localizaciones y la variante sólida — la menos frecuente—, predomina en el nervio óptico (49).

\section{Hallazgos en imágenes}

En TC se observa como una masa predominantemente quística en el vermis o en los hemisferios cerebelos, con área sólida de baja densidad. Ocasionalmente muestra calcificaciones y la hemorragia es rara $(34,50)$.

En RM potenciada en T1 se ve una lesión quística de baja o ligeramente alta señal al LCR, con áreas sólidas de media o baja señal. En secuencias potenciadas en T2 se ven áreas sólidas de alta señal a la sustancia gris, con contenido del quiste de media a alta señal al LCR. En secuencias FLAIR se ven áreas sólidas de alta señal a la sustancia 
gris y el contenido del quiste no se suprime, por lo que aparece como alta señal al LCR. Después de la administración del medio de contraste se observa realce intenso del componente solido $(5,49-51)$ (figura 6).

En secuencias de difusión la porción sólida tiene difusión similar a la sustancia gris con coeficientes de difusión aparente ADC altos. El ADC nunca muestra restricción a la difusión $(17,21,50,52)$ (figura 6).

En las secuencias de espectroscopia se observa aumento de la colina con disminución del NAA y creatina. También, lípidos y lactato. La relación colina/NAA suele estar elevada (entre 1,80 y 3,40) $(22,23,48,52)$.

En secuencias de perfusión se observa bajo volumen sanguíneo cerebral en contraste con el alto realce posterior a la administración de medio de contraste. Los valores de rCBV menores a 1,5 y una curva característica en la fase de recuperación de la curva con aumento de la intensidad por encima de la línea de base se deben a pérdida del medio de contraste hacia el espacio intersticial y aumento de la permeabilidad $(49,50,53-55)$.

\subsubsection{Hemangiob/astoma}

El hemangioblastoma es el tumor primario de fosa posterior más frecuente en adultos, se encuentra con más frecuencia en cerebelo, tronco del encéfalo y médula espinal. La mayoría son tumores esporádicos; sin embargo, aproximadamente $25 \%$ son familiares asociados al síndrome de Von Hippel-Lindau, se presentan típicamente como hemangioblastomas múltiples en pacientes jóvenes. Se manifiestan con signos de hipertensión endocraneana como cefalea, vómitos, ataxia o dismetría $(5,12,56)$.

La OMS lo clasifica como tumor mesenquimal grado I. Estos son altamente vasculares y típicamente intraaxiales, localizados cerca de la superficie pial del cerebelo y la médula espinal. Pueden tener diseminación leptomeníngea al espacio subaracnoideo como hemangioblastomatosis (12).

La apariencia clásica es de masa intraaxial en fosa posterior con quiste y nódulo mural reforzado que contacta con la piamadre, con grandes vasos supliendo la lesión mural que presentan vacío de señal. La lesión quística está rodeada de parénquima cerebral que puede tener gliosis reactiva sin infiltración tumoral. El $40 \%$ se presentan como nódulos sólidos sin quiste asociado. Probablemente, todos los hemangioblastomas inician como nódulos sólidos frecuentemente pequeños y asintomáticos con hiperpermeabilidad vascular y extravasación de plasma con edema vasogénico y formación de quiste $(5,12,57)$.

\section{Hallazgos en imágenes}

En TC se observa lesión quística de baja densidad con nódulo de media densidad que realza tras la aplicación del medio de contraste. Las calcificaciones son extremadamente raras y puede presentar hemorragia por la hipervascularidad (37,57-59) (figuras 7 y 8).

En RM, en secuencias ponderadas en T1, se ve un nódulo de señal intermedia con el encéfalo, vacíos de flujo y alta señal ligera/moderada del quiste en comparación con el líquido cefalorraquídeo (LCR). En secuencias con información T2 el nódulo y quiste tienen alta señal, con vacíos de flujo prominentes. En secuencia FLAIR se observan tanto el nódulo como el quiste con alta señal. El nódulo realza intensamente con medio de contraste, es raro observar realce de la pared del quiste $(5,12,34,60-62)$ (figuras 7 y 8$)$.

En las secuencias de difusión se observa elevado ADC en las porciones quística y sólida relacionado con gran cantidad de capilares dentro del tumor, con valores mayores de 1 similares al LCR $(21,42,53)$ (figuras 7 y 8 ).

En la secuencia de espectroscopia se observa mínima elevación del pico de colina, se pueden ver lípidos por la porción quística. En las secuencias de perfusión se observa marcado aumento del volumen sanguíneo cerebral (rCBV) con valor de rCBV promedio de 26,6 con rangos de $18,34-40,75$ y aumento de la permeabilidad $(53,63,64)$.

\subsubsection{Neurocisticercosis intraventricular (IV ventrículo)}

La neurocisticercosis (NCC) es la infección helmíntica más importante del sistema nervioso central en el mundo, la cual ocurre cuando por contaminación fecal-oral los humanos ingieren los huevos de la Tenia solium y se convierten en huéspedes intermediarios; las oncoesferas migran por vía hematógena a varios tejidos, más frecuentemente al sistema nervioso central, ojos, músculos y tejido celular subcutáneo. Una vez alcanza el tejido neural, el parásito pasa por cinco etapas: no quístico, vesicular, vesicular-coloidal, nodular-granulomatoso y nodular-calcificado (65-70).

Según el lugar en que el cisticerco se aloje, la NCC puede ser parenquimatosa, subaracnoidea, ventricular o medular. En la forma intraventricular la larva alcanza los ventrículos vía plexos coroides y causa síntomas por obstrucción del flujo de líquido cefalorraquídeo y/o ependimitis $(66,71-73)$.

\section{Hallazgos en imágenes}

En TC aparecen como lesiones de baja densidad que agrandan el cuarto ventrículo y causan hidrocefalia. Muchos tienen densidad intermedia al LCR y solo se infieren cuando se observa alteración de la forma del ventrículo, lo cual puede ser un reto diagnóstico especialmente si no existen lesiones parenquimatosas calcificadas asociadas (74).

En RM los quistes usualmente se comportan con señal similar al LCR en secuencias potenciadas en T1 y T2. La pared del quiste se puede observar como estructura lineal de baja señal en secuencias T2 o puede demostrar realce tras la administración del medio de contraste, con deformidad o distensión del cuarto ventrículo asociado a hidrocefalia. En secuencia FLAIR se puede observar con discreta mayor señal comparado con el LCR. La presencia de escólex se observa como un foco de alta señal excéntrica en el quiste, lo cual se considera un criterio absoluto para el diagnóstico de neurocisticercosis. Con medio de contraste se puede observar realce de la pared del quiste o realce ependimario si existen cambios inflamatorios asociados $(67,68,71,74-77)$ (figura 9).

Las secuencias de alta resolución para cisternografía mejoran la visualización de los quistes intraventriculares, las cuales pueden demostrar el escólex. Estas secuencias deben incluirse siempre ante sospecha de neurocisticercosis. En las secuencias de espectroscopia la NCC se comporta similar a los abscesos piógenos con aumento de colina, lactato, succinato, alanina, lípidos y acetato, con disminución de creatina y n-acetilaspartato (78-80).

En las secuencias de difusión se observa señal similar al LCR, con $\mathrm{ADC}$ altos, lo que lo diferencia de los abscesos piógenos que presentan restricción de la difusión con ADC bajos. Sin embargo, cuando existe escólex, este se muestra con alta señal en la secuencia de difusión. En la RM de perfusión no se observa aumento del rCBV en la sustancia blanca, lo que refleja ausencia de angiogénesis y de hiperperfusión $(78,81,82)$ (figura 9). 

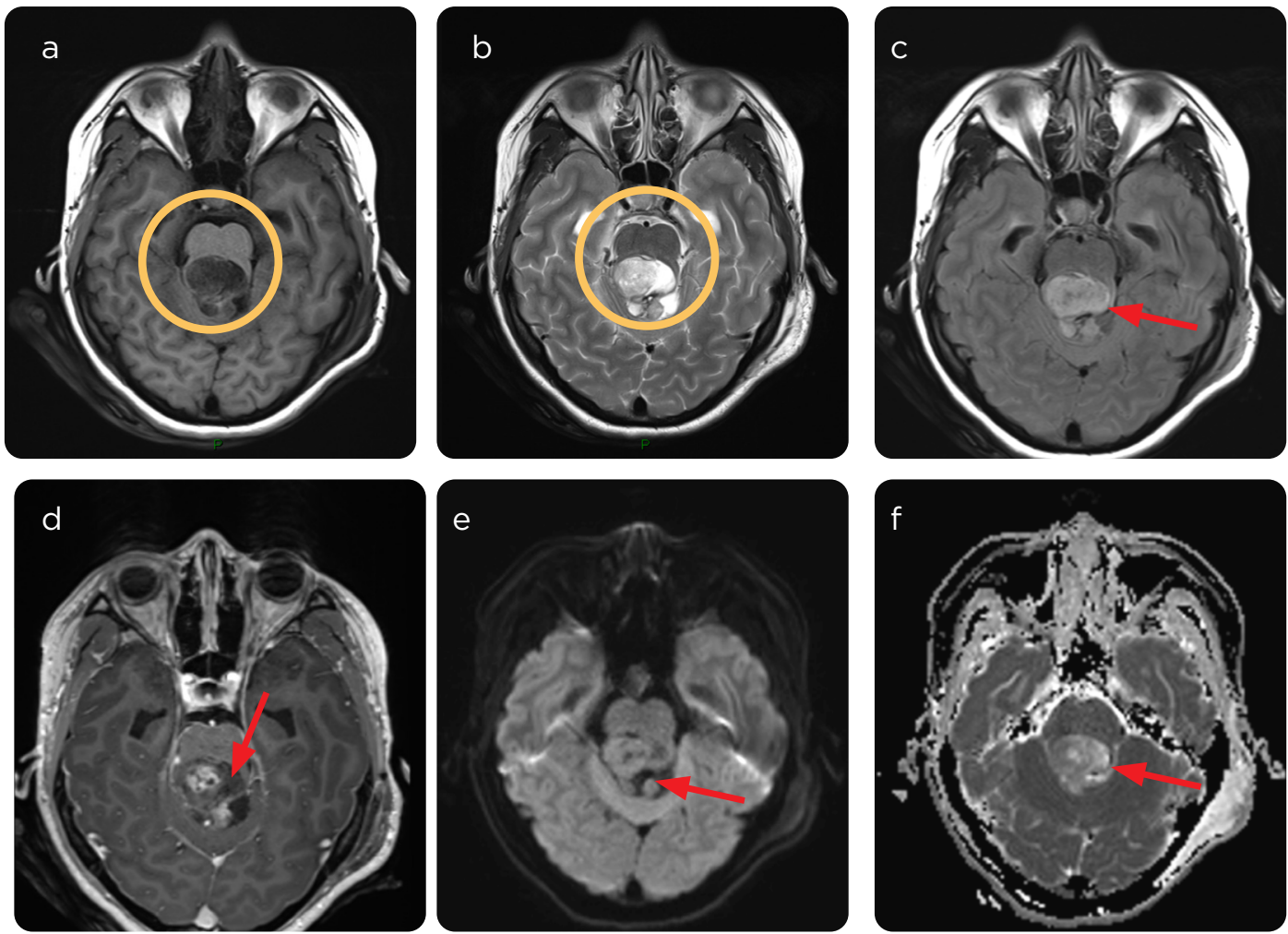

Figura 5. Meduloblastoma. a) RM con información T1: baja señal. b) Secuencia eco de espín y c) FLAIR con información T2: de alta señal. d) Con medio de contraste: realce heterogéneo. e y f) Secuencias de difusión y mapa de ADC: algunas zonas con restricción a la difusión de agua.
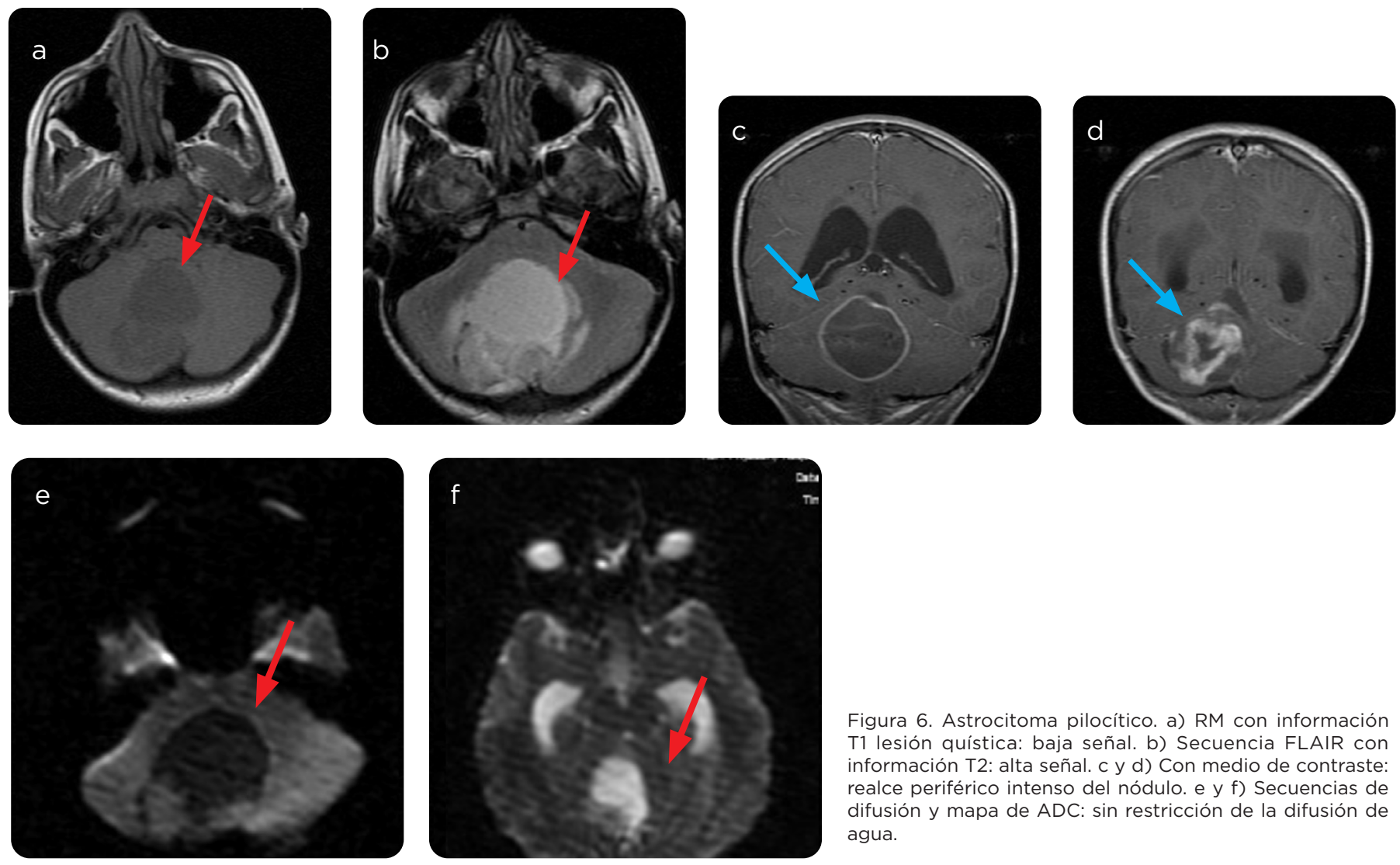

Figura 6. Astrocitoma pilocítico. a) RM con información T1 lesión quística: baja señal. b) Secuencia FLAIR con información T2: alta señal. c y d) Con medio de contraste: realce periférico intenso del nódulo. e y f) Secuencias de difusión y mapa de ADC: sin restricción de la difusión de agua. 

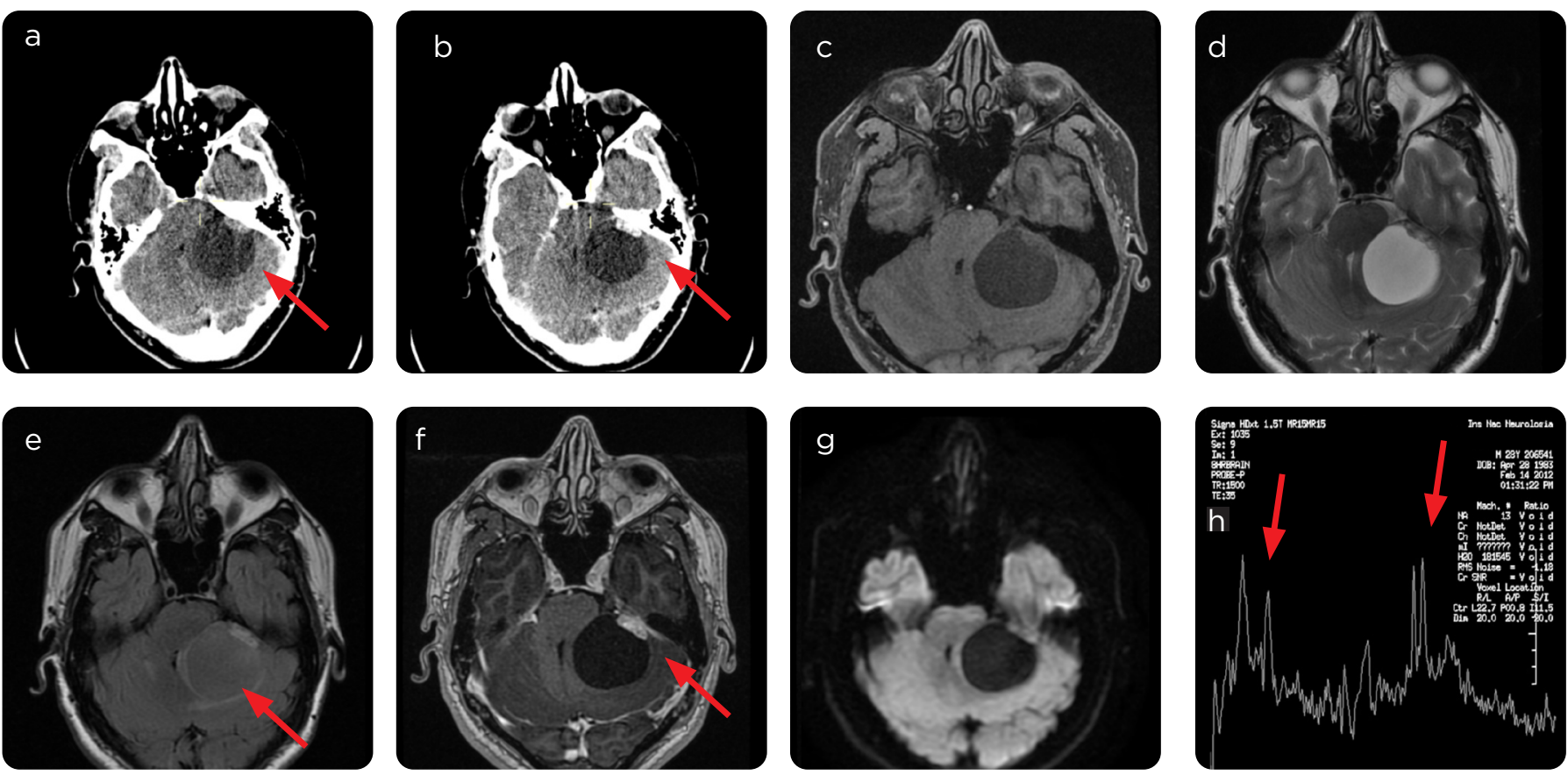

Figura 7. Hemangioblastoma. a) TAC simple y b) con medio de contraste: lesión de baja densidad bien delimitada en el hemisferio cerebeloso izquierdo, con compresión del cuarto ventrículo. c) RM secuencia con información T1: baja señal. d) Secuencias con información T2: alta señal. e) Secuencia FLAIR supresión parcial de la señal. f) Con medio de contraste: nódulo mural que realza homogéneamente con el gadolinio. g) Secuencia de difusión no presenta restricción a la difusión de agua. h) Espectroscopia: leve aumento del pico de colina y aumento del pico de lípidos en la porción quística.
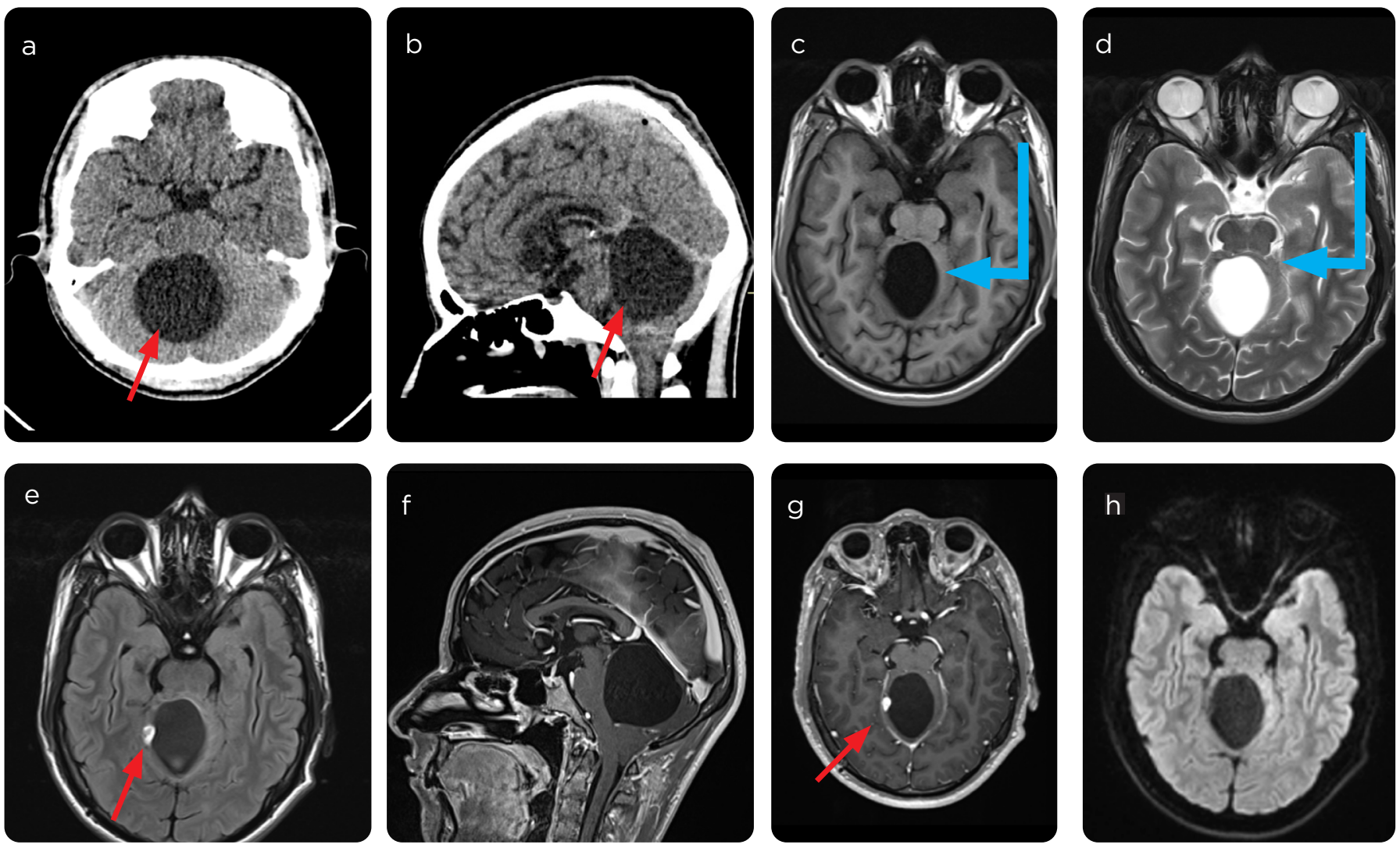

Figura 8. Hemangioblastoma. a) TC axial y b) sagital: lesión de densidad similar al LCR, bien delimitada del vermis cerebeloso. c) RM secuencias con información T1: baja señal. d) Secuencias eco de espín y e) FLAIR con información T2, de alta señal con nódulo mural de señal intermedia similar la sustancia gris. f y g) Con medio de contraste: realce homogéneo. h) Secuencia de difusión: sin restricción de la difusión de agua. 

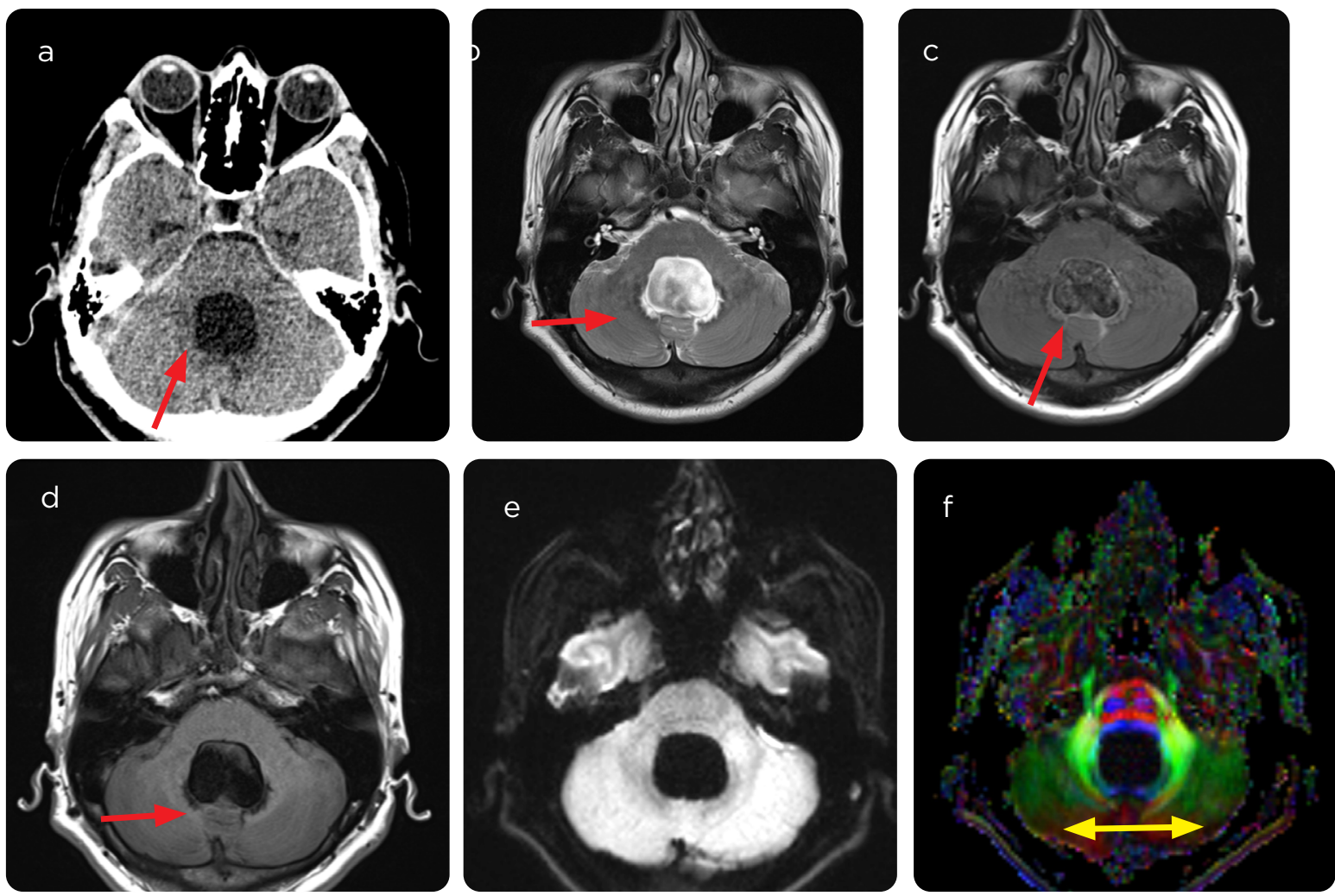

Figura 9. Cisticerco en estadio vesicular coloidal que ocupa el IV ventrículo. a) TC axial lesión similar al LCR. b) RM eco de espín y FLAIR con información T2 lesión heterogénea con mayor señal y con escaso edema perilesional. d) Secuencia con información T1 señal similar al LCR. e) Secuencia de difusión sin restricción a la difusión y f) tractografía mapa de color: desplazamiento de los tractos de sustancia blanca adyacentes al cisticerco.

\section{Conclusión}

Teniendo en cuenta la clínica, los datos demográficos y los hallazgos imagenológicos con técnicas rutinarias de imagen, así como las técnicas avanzadas de difusión, perfusión y espectroscopia, se puede establecer un diagnóstico más preciso ante una lesión que compromete primaria o secundariamente el cuarto ventrículo.

\section{Referencias}

1. Fontana H, Belziti H, Requejo F, Recchia M. Buratti S. Los recesos del IV ventrículo. Rev Argent Neuroc. 2006; 20:101-13

2. Agarwal A, Kanekar S. Intraventricular tumors. Semin Ultrasound CT MRI 2016:37:150-8

3. Koeller K, Sandberg G. Cerebral intraventricular neoplasms: radiologic-pathologic correlation. Radiographics. 2002;(22):1473-505.

4. Smith A, Simirniotopoulos J. Horkanyne-Szakaly I. Intraventricular Neoplasms: Radiologic- Pathologic Correlation. RadioGraphics. 2013;33:21-43.

5. Salgado A, Shehadeh S, Morales E, Santamarta E, Morán M, Saiz A, Oviedo E Lesiones inusuales de la fosa posterior. Hallazgos de Neuroimagen. S-1299 SERAM.

6. Wolff J, Sajedi M, Brant R, Coppes M, Egeler R. Choroid plexus tumours. Br J Cancer. 2002;87:1086-91.

7. Jusué I, Ortega M, Tamarit M, Poveda P. Papiloma atípico de los plexos coroideos en el adulto: publicación de un caso clínico y revisión de la bibliografía. Neurocirugía. 2012;23(3):116-21

8. Louis D, Perry A, Reifenberger G, Von Deimling A, Figarella-Branger D, Cavenee W, et al. The 2016 World Health Organization Classification of Tumors of the Central Nervous System: a summary. Acta Neuropathol. 2016;131:803-20.

9. Fenchel M, Beschorner R, Naegele T, Korn A, Ernemann U, Hoger M. Primarily solid intraventricular brain tumors. Eur J Radiol. 2012;81:e688-96.

10. Hernández P, Villanueva M, Vacas M, Sánchez J, Asensio J, Villanueva J. Tumores intraventriculares: Revisión de los hallazgos radiológicos característicos mediante TC y RM convencional. Congreso de la SERAM; 2012, mayo 24-28. Disponible en: https://epos.myesr.org/poster/esr/seram2012/S-1331.
11. Zabala I, Llorente S, Laganâ C, Barbosa del Olmo A, Cigüenza Sancho M, Gordillo Vélez CH. Tumores intraventriculares: Nuevas entidades y hallazgos recientes en resonancia magnética. Congreso de la SERAM; 2014. Disponible en: https://epos. myesr.org/poster/esr/seram2014/S-0546.

12. Shih RY, Smirniotopoulos JG. Posterior fossa tumors in adult patients. Neuroimag Clin N Am. 2016;26:493-510.

13. Bohara M, Baru M, Fujio S, Higashi M, Yonezawa H, Karki P, et al. Choroid plexus tumors: experience of 10 cases with special references to adult cases. Neurol Med Chir. 2015;55:891-900.

14. Krieger MD, Panigrahy A, McComb JG, Nelson MD, Liu X, González-Gómez I, e al. Differentiation of choroid plexus tumors by advanced magnetic resonance spectroscopy. Neurosurgical focus. 2005;15:18(6A).

15. Verma A, Kumar I, Verma N, Aggarwal P, Ojha R. Magnetic resonance spectroscopy - Revisiting the biochemical and molecular milieu of brain tumors. BBA Clinical. 2016;5:170-8.

16. Grossman R, Ram Z. Posterior fossa intra-axial tumors in adults. World Neurosurg. 2016;88:140-5. doi: 10.1016/j.wneu.2015.12.066.

17. Raynaud C, Ramaswamy V, Taylor M, Laughlin S. Posterior fossa tumors in children: Developmental anatomy and diagnostic imaging. Childs Nerv Syst. 2015;31:1661-76.

18. Thompson YY, Ramaswamy V, Diamandis P, Daniels C, Taylor MD. Posterior foss ependymoma: current insights. Childs Nerv Syst. 2015;31:1699-706.

19. Sayegh ET, Aranda D, Kim JM, Oh T, Parsa AT, Oh MC. Prognosis by tumor location in adults with intracranial ependymomas. J Clin Neurosci. 2014;21(12):2096-101.

20. U-King-Im JM, Taylor MD, Raybaud C. Posterior fossa ependymomas: new radiological classification with surgical correlation. Childs Nerv Syst. 2010;26:1765-72.

21. Olabarria IV, Villanúa JA, Fernández B, Ontañon JM, Cabrera A, Saralegui I. Tumores de fosa posterior y Difusión. Congreso Seram. Granada; 24-28 de mayo de 2012. Disponible en: https://epos.myesr.org/poster/esr/seram2012/S-0891.

22. Brandão LA, Castillo M. Adult brain tumors clinicalapplications of magnetic resonance spectroscopy. Magn Reson Imaging Clin N Am. 2016;24:781-809.

23. Majós C, Aguilera C, Cos C, Camins À, Candiota AP, Delgado-Goñi T, et al. In vivo proton magnetic resonance spectroscopy of intraventricular tumours of the brain. Eur Radiol. 2009;19:2049-59.

24. Kim Y, Lee SY, Yi KS, Cha S, Gang M, Cho B, et al. Infratentorial and Intraparenchymal Subependymoma in the Cerebellum: Case Report. Korean J Radiol. 2014;15(1):151-5. 
25. Landriel F, Besada C, Migliaro M, Christiansen S, Goldschmidt E, Yampolsky C, et al. Atypical hemorrhagic presentation of a fourth ventricle subependymoma: Case Report. Neurol Med Chir (Tokyo). 2013;53:828-31.

26. Jain A, Amin AG, Jain P, Burger P, Jallo GI, Lim M, et al. Subependymoma: clinical features and surgical outcomes. Neurol Res. 2012;34(7):677-84.

27. Burguete A. WHO grade I intraventricular tumors: findings in diffusion, perfusion and spectroscopy. Congreso SERAM C-1990. Coruña 2012. Disponible en: https:// epos.myesr.org/poster/esr/ecr2012/C-1990.

28. Ragel BT, Osborn AG, Whang K, Townsend JJ, Jensen RL, Couldwell WT. Subependymomas: An analysis of clinical and imaging features. Neurosurgery. 2006;58:881-90.

29. Alver I, Abuzayed B, Kafadar AM, Muhammedrezai S, Sanuz GZ, Akar Z. Primary Fourth Ventricular Meningioma: Case Report and Review of the Literature. Turkish Neurosurgery. 2011;21(2):249-253.

30. Takeuchi S, Sugawara T, Masaoka H, Takasato Y. Fourth ventricular meningioma: a case report and literature review. Acta Neurol Belg. 2012;112:97-100.

31. Khedr S, Hassaan M, Refaat A. The diagnostic value of diffusion weighted imaging in patients with meningioma. Egyptian J Radiol Nuclear Med. 2012;43:249-56.

32. Cabada T, Caballero M, Insausti I, Álvarez de Eulate N, Bacaicoa C, Zazpe I, et al. Papel de la difusión en la evaluacion de los meningiomas: correlación radiopatológica. Radiología. 2009;51(4):411-9.

33. Yin B, Liu L, Zhang B, Li YX, Li Y, et al. Correlating apparent diffusion coefficients with histopathologic findings on meningiomas. Eur J Radiol. 2012;81:4050-6.

34. Poretti A, Meoded A, Huisman T. Neuroimaging of pediatric posterior fossa tumors including review of the literature. J Magnetic Resonance Imag. 2012;35(1):32-47.

35. Coyle B, Kessler M, Sabnis D, Kerr I. ABCB1 in children's brain tumours. Biochem Soc Trans. 2015;43(5):1018-22.

36. Massimino M, Biassoni V, Gandola L, Garrè M, Gatta G, Giangaspero F, et al. Childhood medulloblastoma. Crit Rev Oncol/Hematol. 2016;105:35-51. http://dx.doi. org/10.1016/j.critrevonc.2016.05.012.

37. Bartlett F, Kortmann R, Saran F. Medulloblastoma. Clin Oncol. 2013;25(1):36-45.

38. Taylor M, Northcott P, Korshunov A, Remke M, Cho Y, Clifford S, et al. Molecular subgroups of medulloblastoma: the current consensus. Acta Neuropathol. 2012;123(4):465-72

39. Northcott P, Korshunov A, Pfister S, Taylor M. The clinical implications of medulloblastoma subgroups. Nat Rev Neurol. 2012;8(6):340-51. doi:10.1038/nrneurol.2012.78.

40. Martínez M. Meduloblastoma pediátrico, revisión y puesta al día. Radiología. 2011;53(2):134-45.

41. Yamashita Y, Kumabe T, Higano S, Watanabe M, Tominaga T. Minimum apparent diffusion coefficient is significantly correlated with cellularity in medulloblastomas. Neurological Research. 2009;31(9):940-6.

42. Abdul Z, Saini J, Ranjan M, Gupta A, Sabharwal P, Purushotham N. Diffusion tensor imaging in evaluation of posterior fossa tumors in children on a 3T MRI scanner. Indian J Radiol Imaging. 2015;25(4):445-52.

43. Pierce T, Kranz P, Roth C, Leong D, Wei P, Provenzale J. Use of apparent diffusion coefficient values for diagnosis of pediatric posterior fossa tumors. Neuroradiol J. 2014;27:233-44.

44. Rodríguez D, Awwad A, Meijer L, Manita M, Jaspan T, Dineen R, et al. Metrics and textural features of MRI diffusion to improve classification of pediatric posterior fossa tumors. Am J Neuroradiol. 2014;35:1009-15.

45. Rumboldt Z, Camacho D, Lake D, Welsh C, Castillo M. Apparent diffusion coefficients for differentiation of cerebellar tumors in children. Am J Neuroradiol. 2006:27:1362-9.

46. Jouanneau E, Guzmán R, Desuzinges C, Frappaz D, Louis-Tisserand G, Sunyach $\mathrm{MP}$, et al. Very late frontal relapse of medulloblastoma mimicking a meningioma in an adult: Usefulness of H-Magnetic resonance spectroscopy and diffusion-perfusion magnetic resonance imaging for preoperative diagnosis: case report. Neurosurgery. 2006;58:789-90.

47. Baker S, Ellison D, Gutmann D. Pediatric gliomas as neurodevelopmental disorders. Glia. 2016;64(6):879-95.

48. Helfferich J, Nijmeijer R, Brouwer O, Boon M, Fock A, Hoving E, et al. Neurofibromatosis type 1 associated low grade gliomas: A comparison with sporadic low grade gliomas. Critical Rev Oncol/Hematol. 2016;104:30-41.

49. Arango J, Menor F, Viguer R, Esteban M, Palacios P, Assing O. Astrocitoma pilocítico pediátrico. Aproximación diagnóstica con TC y RM. Congreso de la SERAM 2012. Disponible en: https://epos.myesr.org/poster/esr/seram2012/S-0744.

50. Gaudio S, Martucci M, Russo R, Visconti E, Gangemi E, D’Argento F, et al. MR imaging of brain pilocytic astrocytoma: beyond the stereotype of benign astrocytoma. Childs Nerv Syst. 2017;33(1):35-54.

51. Collins V, Jones D, Giannini C. Pilocytic astrocytoma: pathology, molecular mechanisms and markers. Acta Neuropathol. 2015;129:775-88.

52. Docampo J, González N, Muñoz A, Bruno C, Morales C. Astrocitoma pilocítico. Formas de presentación. Rev Argent Radiol. 2014;78(2):68-81.

53. Brandão L, Shiroishi M, Law M. A Multimodality approach with diffusion- weighted imaging, diffusion tensor imaging, magnetic resonance spectroscopy, dynamic susceptibility contrast and dynamic contrast-enhanced magnetic resonance imaging. Magn Reson Imaging Clin N Am. 2013;21(2):199-239.

54. Grand S, Kremer S, Tropres I, Hoffmann D, Chabardes S, Lefournier V, et al. Perfusion-sensitive MRI of pilocytic astrocytomas: initial results. Neuroradiology. 2007;49(7):545-50.
55. Uematsu H, M Maeda. Double-echo perfusion-weighted MR imaging: basic concepts and application in brain tumors for the assessment of tumor blood volume and vascular permeability. Eur Radiol. 2006;16(1):180-6.

56. Findeis-Hosey JJ, McMahon KQ, Findeis SK. Von Hippel-Lindau Disease. J Pediatr Genet. 2016;5(2):116-23. http://dx.doi.org/ 10.1055/s-0036-1579757.

57. Schunemann V, Huntoon K, Lonser RR. Personalized medicine for nervous system manifestations of von Hippel-Lindau Disease. Front Surg. 2016;3:39.

58. Wang $\mathrm{Z}, \mathrm{Hu} \mathrm{J}, \mathrm{Xu} \mathrm{L}$, Malaguit J, Chen S. Intratumoral hemorrhage in a patient with cerebellar hemangioblastoma a case report and review. Medicine (Baltimore). 2015;94(4):e497.

59. Osorio D, Guevara J. Diagnóstico de hemangioblastoma por tomografía computarizada. Concordancia interobservador. Rev Med IMSS. 2002;40(5):393-7.

60. Arora R. Imaging spectrum of cerebellar pathologies: A pictorial essay. Pol J Radiol. 2015;80:142-50.

61. Leung R, Biswas S, Duncan M, Rankin S. Imaging features of von HippelLindau Disease. RadioGraphics. 2008;28:65-79.

62. Raz E, Zagzag D, Saba L, Mannelli L, Paolo P, Ambrosio F, et al. Cyst with a mura nodule tumor of the brain. Cancer Imaging. 2012;12:237-44

63. Guan T, Pancharatnam D, Chandran H, Hooi T, Kumar G, Ganesan D. Infratentoria benign cystic meningioma mimicking a hemangioblastoma radiologically and a pilocytic astrocytoma intraoperatively: a case report. J Medical Case Reports. 2013;7:87.

64. Cho S, Na D, Ryoo J, Roh H, Moon C, Byun H, et al. Perfusion MR Imaging: Cli nical utility for the differential diagnosis of various brain tumors. Korean J Radiol. 2002:3:171-9.

65. Jensen T, Post J. Intraventricular neurocysticercosis: Presentation, diagnosis and management. Asian Pacific Journal of Tropical Medicine. 2016;9(8):815-8. http:/ dx.doi.org/10.1016/ j.apjtm.2016.06.016

66. Sinha S, Sharma B. Intraventricular neurocysticercosis: a review of current status and management issues. Br J Neurosurg. 2012;26(3):305-9.

67. Kimura ET, Higuera JA, Corona R, Chávez L, Perochena A, Quiroz L, et al. Neurocysticercosis: Radiologic-Pathologic Correlation. RadioGraphics. 2010;30(6):1705-19.

68. Sarria S, Frascheri L, Siurana S, Auger C, Rovira A. Neurocisticercosis. Hallazgos radiológicos. Radiología. 2013;55(2):130-41.

69. Del Brutto $\mathrm{OH}$. Neurocisticercosis: actualización en diagnóstico y tratamiento. Neurología. 2005;20(8):412-8

70. Shih R, Koeller K. Bacterial, fungal, and parasitic infections of the central nervous system: Radiologic-pathologic correlation and historical perspectives. RadioGraphics. 2015;35:1141-69.

71. Sánchez A, Monteagudo M, Lozano E, García J. Neurocisticercosis racemosa subaracnoidea gigante y ventricular: a propósito de un caso. Rev Argent Microbiol. 2015;47(3):201-5

72. Teerasukjinda $\mathrm{O}$, Wongjittraporn $\mathrm{S}$, Tongma $\mathrm{C}$, Chung H. Asymptomatic giant intraventricular cysticercosis: A Case Report. Hawaii J Med Public Health. 2016;75(7):187-9.

73. Matushita H, Campos F, Dante D, Jacobsen M. Hydrocephalus in neurocysticercosis Childs Nerv Syst. 2011;27(10):1709-21

74. Del Brutto OH. Neurocysticercosis. The Neurohospitalist. 2014;4(4):205-12.

75. Del Brutto OH. Neurocysticercosis: A Review. Scientific World J. 2012;2012:1-8. https://doi.org/10.1100/2012/159821

76. Lucato L, Guedes M, Sato J, Bacheschi L, Machado L, Leite C. The role of conventiona MR imaging sequences in the evaluation of neurocysticercosis: impact on characterization of the scolex and lesion Burden. Am J Neuroradiol. 2007;28(8):1501-4.

77. Delgado R, Boleaga B, Salgado P. Magnetic resonance imaging in neurocysticercosis. Top Magn Reson Imaging. 2014;23:191-8.

78. Lerner A, Shiroishi M, Zee C, Law M, Go J. Imaging of neurocysticercosis. Neuroimag Clin N Am. 2012;22:659-76.

79. Carpio A, Fleury A, Hauser WA. Neurocysticercosis Five new things. Neurol Clin Pract. 2013;3(2):118-25

80. Brandao MD, Lara A, Domingues RC. MR spectroscopy of the brain. Philadelphia, PA: Lippincott Williams \& Wilkins; 2004

81. Raffin L, Bacheschi L, Machado L, Nóbrega J, Coelho C, Leite C. DiffusionWeighted MR imaging of cystic lesions of neurocysticercosis. Arq Neuropsiquiatr 2001;59(4):839-42.

82. Santos G, Leite C, Machado L, McKinney A, Lucato L. Reduced diffusion in neurocysticercosis: Circumstances of appearance and possible natural history implications. Am J Neuroradiol. 2013;34(2):310-6.

\section{Correspondencia}

Carlos Andrés Arias Durán

Conjunto Mirador de Versalles, torre 4, apartamento 1213

Floridablanca, Santander

cariasduran6@gmail.com

Recibido para evaluación: 10 de junio de 2020

Aceptado para publicación: 29 de julio de 2020 